\title{
Financial Self-Service Transaction Method Based on Wireless Communication Network
}

\author{
Wangsong Xie $\mathbb{D}$ \\ Business School, Wuxi Taihu University, Wuxi 214064, Jiangsu, China \\ Correspondence should be addressed to Wangsong Xie; xiewangsong@126.com
}

Received 5 January 2022; Revised 24 January 2022; Accepted 3 February 2022; Published 24 February 2022

Academic Editor: Ahmed Farouk

Copyright (c) 2022 Wangsong Xie. This is an open access article distributed under the Creative Commons Attribution License, which permits unrestricted use, distribution, and reproduction in any medium, provided the original work is properly cited.

With the advent of the new era and the rapid development of the service industry, a self-contained terminal control business with its high-performance operation provides reliable information, saves a lot of manpower and time resources, and maintains flexibility, thus becoming an insignificant and important part of the financial services industry. This article aims to study the financial self-service transaction method based on a wireless communication network. This article starts from three stages such as functional planning, future direction, and final management and makes every effort to help the bank focus on three-dimensional and intelligent development of main business channel services from three levels such as technology, facilities, and channels, so as to realize the banking business from "production and direction" to "the transformation of marketing and experience," providing end users with a brand-new work experience at anytime and anywhere to increase productivity and reduce labor costs. The research results show that more than $80 \%$ of the interviewed people have expressed affirmation of the financial self-service transaction service under the wireless communication network, and the interactive design of the operation interface and the information data and security system need to be further improved.

\section{Introduction}

Although the prospect of "my country's wireless communication network" is bright, its development is far from human expectations [1]. With the rapid development of society, financial services have penetrated each of our worlds. In the past, we had to go to the bank to queue up for business. Now, we can handle business on personal terminals and enjoy $24 \times 365$ uninterrupted services. Financial services are closely related to the lives of each of us [2].

With the development of financial information construction and applications, users have more and more needs for financial transaction services [3]. In order to efficiently and promptly respond to user requests for autonomous financial services, it is necessary to develop a set of financial self-service transaction service systems based on wireless communication networks to realize the mobilization of operation and maintenance works, thereby improving the service level of the network center and enhancing users' financial transaction self-service experience. In order to better serve customers, reduce the labor intensity of tellers, and improve the level of financial services, it will become an inevitable trend for transactions to turn to self-service equipment $[4,5]$. As a bank's well-functioning and convenient port of call, the role of ATM is obvious. It is the bank's self-service window, providing customers with convenient and fast financial services every day, and is the bank's window image.

At present, there are few researches on financial selfservice terminals at home and abroad. From the application point of view, the financial self-service terminal can be regarded as a special self-service financial service terminal [6]. Introducing the Internet of Things into the financial service industry and exploring the driving costs and processes of financial innovation are important milestones in accelerating the promotion of financial innovation. From the perspective of banks and other supply-chain financial institutions, Li takes mainstream trading products in the commodity-trading market as the research object, adopts the LA-VAR model, and fully considers the market-price 
fluctuations and liquidity factors of supply-chain finance. The theoretical basis for the continuous innovation of rural financial products is analyzed. On the basis of analyzing the basic characteristics and types of rural financial product innovation, the connotation of rural financial product sustainable innovation is explored, evaluation criteria are clarified, and a theoretical foundation for continuous dynamic evaluation is laid [7]. Estrella-Ramon's study extends the diffusion of innovation theories and technology acceptance models that are applicable to describe and model the behaviors observed by individual customers during the preadoption phase of the adoption process. The log-logistic parameter survival model uses panel data to apply from 1,357 new customers randomly selected by the bank. There are significant differences between the survey results and the cycle of bank interaction, the number of products involved in the interaction, and the convenience of interaction and customer behavior related to risks. The results confirm that customers who are more likely to adopt online banking faster show offline-behavior patterns that are more related to higher interaction cycles and convenience [8]. Internet technology has affected the banking system because it can improve the performance of financial services. One of the main problems of the online banking system is the customer's perception of security and trust. Barkhordari conducted an experimental investigation on the important factors affecting the trust of Iran's electronic payment system. A set of potential trust determinants is developed and organized into three main groups: technology and transaction procedures, access to, and availability of security guidelines. In empirical studies, the direct impact of these factors on perceived trust and their indirect impact through perceived security have been evaluated. The data were collected from customers of several Iranian banks. Research has found that perceived security and trust have a positive impact on the use of electronic payment systems. As a result, adherence to technology and transaction procedures, as well as access to security guidelines is the most important factor affecting customer perception of trust [9]. These three researchers all agree that the combination of the Internet and finance can bring huge economic benefits to banks. Although they have conducted experimental studies from different perspectives, how to adjust the banking system with the participation of the Internet, and the effectiveness of the masses have been ignored.

Since the interface interaction design industry of financial transaction self-service terminal service equipment in our country started late, the interface interaction design of self-service terminal equipment used in the market is not yet mature. The user groups served by financial transaction selfservice terminal service equipment are extensive and complex. Among them, there are many user groups with insufficient computer operation experience and low cognitive level. These users cannot fully enjoy the convenience and efficiency provided by modern technology self-service terminal service equipment. The main reason for this situation is that the interactive design of the interface in the financial transaction self-service terminal service equipment is not perfect. The self-service terminal page should be designed more simply and have a voice reminder function. It can also set volunteers at fixed points to guide people in business handling. Therefore, the improvement and perfection of the interactive design method of the financial transaction self-service terminal service equipment interface can make information more accurately and efficiently recognized, understood, and used by users, helping users to complete interactive tasks smoothly and improving user experience to the greatest extent. Interaction design is the embodiment of humanization, which represents the interaction between users and devices. If properly designed, users can easily and quickly complete business and have a good user experience. This study uses "user research and analysisinterface interactive innovation design-interface interactive design details redesign-usability testing" as the research process to explore and study the interface interactive design of financial transaction self-service terminal service equipment and find more suitable financial self-service transactions method.

\section{Wireless Communication Network and Financial Transaction Algorithm}

2.1. Financial Transaction Self-Service Terminal Equipment. With the continuous expansion of banking business, selfservice financial equipment was born. Self-service financial equipment is mainly to meet people's daily needs. It is precise because of its practicality [10] that self-service financial equipment is more and more popular with banks and mobile devices. According to the comprehensive statistics of China's major state-owned banks, national joint-stock banks, urban commercial banks, rural commercial banks, rural credit cooperatives, and other financial institutions in 2016, about 103000 ATMs were newly purchased. Favored by institutions, this kind of self-service financial equipment is mostly 24-hour equipment such as ATM, and the number is large [11]. The user groups of self-service terminals are extensive and complex. For users with low technical level and inexperience, difficulty to understand viewpoints and difficulty to interact will affect their performance and enthusiasm. Therefore, it is necessary to improve the self-service terminal. With the improvement of technology and the improvement of the service industry, self-service terminals are widely used in the fields of finance, transportation, catering, government services, medical care, and retail [12]. Self-service terminals can reduce enterprise operating costs, provide value-added services, reduce the pressure of counter banking industry, and make people's life more convenient. It is expected that in the next few years, the self-service terminal market will enter a high-speed growth period. Self-service terminals will be seen everywhere in business halls, streets, and alleys in cities and even villages, and become an indispensable part of public life. Common self-service terminals around us include bank self-service teller machines, mobile phone self-service top-up machines, and campus transfer machines. Under the social background of the rapid development of information technology, the high-quality service economy based on the digital transmission network mechanism and automated management and control functions is strongly impacting the 
traditional product economy, and the self-service system is precisely this high-quality service economy [13]. The selfservice platform that integrates multiple functions and realizes networked management is still in its infancy, and most of them are running on a stand-alone basis. The functions of the self-service platform include bank information query, personal business, corporate business, bank card transfer, agent payment business, etc. The realization of the financial self-service transaction service system under the wireless communication network can provide a comprehensive management service system integrating network management and intelligent self-service.

Wireless network communication technology has the characteristics of high speed, high penetration, and large capacity drive. Applying information technology to traditional enterprises can improve enterprise work efficiency, reduce energy consumption, improve productivity, and promote the upgrading and reorganization of traditional industries. Information technology provides technical support for system redesign [14-16]. In the past, we had to go to the bank counter to queue up for business. Now, we can operate on the financial self-service terminal device through the application of the wireless communication network and can handle our business needs at anytime and in anyplace with a network signal; on the contrary, in the past, financial services must be arranged in accordance with the bank's commuting time and must be operated by bank staff. On self-service financial equipment, consumers can independently complete the payment of various fees, avoiding the trouble caused by consumers needing to go to different places to pay corresponding fees. Self-service financial equipment not only improves the operational efficiency of the bank but also greatly saves people's time for payment and reduces the difficulty of payment [17]. At present, the financial industry is expanding bank outlets, improving the card environment for customers, providing all-weather and all-round financial services, reducing bank costs, and improving bank service quality and comprehensive competitiveness. At present, the business types managed by customers through electronic channels are growing exponentially at a higher growth rate [18].

2.2. Wireless Communication Network. The advantage of financial transaction self-service is to use the convenience and speed of information service embodied by high-tech means to provide a new self-assisted financial service for the financial service field with large liquidity [19]. On the one hand, the service can better improve the performance of selfservice terminals; on the other hand, it can promote people's convenient life and improve service efficiency. With the need to improve service levels, the demand for self-service terminals in the wireless communication network and financial service industries has grown rapidly, which has also forced banks to turn to a key acceptance point, electronic selfservice terminals [20]. On the wireless communication network, as a very effective service, the personal service terminal can provide person-centered care, attention, and personal service to customers and investigate the influence of the interaction mode between individuals in the system on the overall behavior of the system. Studying the complex network is the ultimate goal to understand the influence of network structure on dynamic energy behavior. When theoretically studying the dynamic characteristics of complex networks, complex networks can be expressed as the structural characteristics of communication networks in the following form [21, 22]. A single node dynamic network connection system can be expressed as follows:

$$
R(t)=v(R(t))+\delta \sum_{i=1}^{m 1} a, \quad i=1,2, \ldots m 1 .
$$

A single node discrete system [23] can be expressed as follows:

$$
R(s+1)=v(R(s))+\sum_{i=1}^{m 1} b, \quad i=1,2, \ldots m 1 .
$$

In the above formula, $R$ represents the state vector of the $i$ node. If $R=0$, it means that the link between network nodes has no directionality. Such a network is called an undirected network [24]. The calculation method of the path length between single nodes is as follows:

$$
\begin{aligned}
& l=\frac{1}{q(q-1)} \sum_{i, i \neq q} k, \\
& l=k \pm \frac{2 a, q}{k_{i}\left(k_{i}-1\right)} \sum_{i, i \neq q}^{1},
\end{aligned}
$$

where $q$ is the number of nodes in the network, and the average path length describes the degree of separation of segments in the network, that is, how small the network is.

The wireless channel is an important part of the communication system such as the transmission medium between the transmitter and the receiver. In order to facilitate the understanding of the wireless communication network, we must first understand its signal transmission principle [25]. In the process of signal transmission from transmitter to receiver, it has to go through a variety of complex transmission paths. The wireless communication network is essentially a composite signal composed of incoming waves from different paths. During the transmission process, the received energy is affected by many factors such as the ground and constraints that affect signal transmission. In general, the received power of the antenna at a distance of the transmitter can be expressed as follows:

$$
D_{r}(a)=\frac{D_{t} P_{r} P_{t} \gamma^{2}}{(4 \cdot 3.14)^{2} a^{2} l} .
$$

$D_{r}$ and $D_{t}$ are the power of the transmitting end and the receiving end, $P_{r}$ and $P_{t}$ are the gains of the transmitting antenna and the receiving antenna, $l$ is the signal transmission distance, and $\gamma$ is the wavelength. When the relative position between the transmitter and the receiver changes slightly, the signal amplitude of the wireless channel will change. According to the Rice distribution [26], the probability density function in this case is as follows: 


$$
\begin{gathered}
g_{\text {Rice }}(O)=\frac{O}{\varepsilon^{2}} \exp \left[-\frac{\left(\lambda^{2}+\chi^{2}\right)}{\left(2 \varepsilon^{2}\right)}\right] i_{1}\left[\frac{o \chi}{\varepsilon^{2}}\right], \quad o \geq 0, \\
g_{\text {Rayleigh }}(o)=\frac{o}{\varepsilon^{2}} \exp \left[\frac{\lambda^{2}}{\left(2 \varepsilon^{2}\right)}\right], \quad o \geq 0 .
\end{gathered}
$$

In equation (2), $\chi$ is the amplitude component of the line-of-sight path, and the ratio of the amplitude component under the line-of-sight path to the sum of the amplitude components under other non-line-of-sight paths is $o \chi / \varepsilon^{2}$. The larger the ratio, the smaller is the amplitude change. The larger the ratio, the greater is the amplitude change [27].

The power control of signal transmission is a very important link in the cellular system $[28,29]$. One of the most important aspects when designing a communication system is how to reduce the transmission capacity of the system. Using power management technology, each user can reduce the antenna power that circulates in the communication quality meeting and at the same time can reduce interference to other users, increase the system capacity, and set the size of the transmission power according to the distance effect and the single user The power regulation in the cellular system is expressed as follows:

$$
\begin{aligned}
& H_{i, p}=T_{i, p} J_{i}(i, p) \uparrow\left(\sum_{i=1}^{n} T_{r, t} J_{i}(r, t)-T_{i, p} J_{i}(r, t)+\beta_{r, t}\right), \\
& H_{i, p}=T_{i, p}\left(\sum_{i=1}^{n} T_{r, t}(i, p)-T_{i, p}+\eta_{i, p}\right),
\end{aligned}
$$

where $T_{i, p}$ represents the transmit power of a single user $i$ in the cellular system, and $\beta_{r, t}$ is the thermal noise of the base station side receiver.

With the development of home communication and electronic technology such as the further integration of communication networks, broadcasting networks, and the Internet, providing users with electronic services has become a constant trend. The demand analysis of the equipment investment of the wireless communication network in the financial self-service transaction service terminal technology can be expressed as follows:

$$
\begin{aligned}
\sum_{t=1}^{N_{t}} & =\frac{n}{2 t}-\sqrt{r_{t}} \sqrt[i]{t(t+1)+1} \\
T & =\left(\int\left(\beta \cdot r_{t}\right) \cdot \sum_{i-1}^{i} p\right)-\left(\overleftarrow{i=0} i_{p-1}\right) .
\end{aligned}
$$

In order to solve the problem of limited or reduced variance model construction in wireless communication networks and personal business services, since the model involves limited reliability variables, the revised model (Tobit) of this survey is selected, which can be expressed as follows [30]:

$$
\begin{aligned}
A_{i} & =A_{i}^{*} \sum(i-1) \delta+\gamma \cdot X_{i}, \\
X_{i=o} & =\sqrt[2]{\left(i \cdot A_{\gamma}\right)} \delta+\delta-\gamma .
\end{aligned}
$$

Using the least square method will lead to unfair and inconsistent values, so the Tobit model is used to analyze the influencing factors of wireless communication network applications in finance.

\section{Application Experiment of Wireless Communication Network in Financial Self- Service Transaction}

3.1. Test Subject. (1) 40 business handling people.

(2) ATM machines and other financial self-service transaction service equipment.

(3) Wireless communication network.

\subsection{Experimental Process}

(1) Research on wireless communication networks and financial self-service transaction services for user experience, a certain postal bank in this city is invited to conduct a questionnaire survey on the business of the day of the survey. The survey content is the experience of commonly used ATM machines and other self-service transaction terminal devices. It senses, understands user needs, and analyzes.

(2) Experimental research is conducted on the internal management of the financial industry, and development prospects of financial self-service transaction equipment combined with wireless communication networks and the areas that need improvement are analyzed and summarized.

(3) Dimensional analysis of the adoption of wireless communication networks and financial self-service transaction methods by the interviewees is carried out.

(4) Interface interaction design analysis of self-service transaction terminal service is carried out.

3.3. Experimental Results. By studying the self-service "man, machine, environment" system, the problems and design goals in the system can be effectively obtained. Through detailed situation investigation of counter services, the integrity of tasks in self-service can be ensured and possible situations can be avoided. Interaction design is dedicated to eliminating the barriers between people and computers, so that people do not feel that computers are high-tech things, but are tools that ordinary people can use as they please. The wireless communication network meets the rapid development of capacity requirements and the development of full services. The optimization of terminal functions to improve the convenience and ease of use of terminal functions is the key to improving customer experience. Wireless communication network plays an extremely important role in financial self-service transaction services. 


\section{Application of Wireless Communication Network in Financial Self-Service Transaction Service}

The self-service channel of bank services has been unanimously recognized by the majority of users, providing customers with a brand-new self-assisted financing method. Banks are taken as an example. In 2012, China's e-banking (including online banking, mobile banking, ATM, selfservice terminal, and other forms of self-service e-banking) transactions reached 89.62 billion, and the e-banking replacement rate increased to $72.3 \%$.

However, the requirements for bank self-service terminals are also gradually changing, so the management difficulty is becoming more and more difficult. How to better improve management efficiency and form advanced bank self-service terminals have been paid more and more attention by banks and related industries. In order to meet the information processing needs of bank self-service, technical specifications on the development of bank self-service terminal and related user data standards are formulated, and an integrated structural system and technical system are proposed for bank self-service terminal design. It can better allocate the personal data and business logic processing information of self-service bank users, divide the permissions of business processors, users, and system administrators in detail, and build a high-level bank self-service terminal. A simulation diagram of the application process of a wireless communication network and a self-service transaction service is shown in Figure 1.

The people no longer need to wait for a long time to go to the counter to handle business but directly complete inquiries, deposits, withdrawals, transfers, supplementary bills, payment, and other services through financial self-service terminals, which saves users' time and improves financial payments. The environment has also improved the service level of credit cooperatives, further enhanced the market competitiveness of credit cooperatives, and improved the social image of credit cooperatives. We conducted a questionnaire survey on the use and usability of ATMs of the current common financial self-service transaction equipment. We selected 40 people from a postal bank in this city who came to the bank for business processing that day. Table 1 lists the basics of the interviewed people's information.

The interviewed people have different education levels and can conduct targeted data analysis on ATM self-service teller machines and other financial self-service transaction terminal equipment; according to their different experiences, they can understand the needs of different levels of subjects. The user groups of self-service terminals are extensive and complex. For users with low technical level and inexperience, difficulty to understand viewpoints and difficulty to interact will affect their performance and enthusiasm. Therefore, it is necessary to improve the self-service terminal. Table 2 lists the differences in preferences of different genders for financial self-service transaction services; Figure 2 shows the statistical data of these respondents' understanding of financial selfservice transaction equipment.

It can be seen from Table 2 that under the $95 \%$ confidence level, the implicit attitudes of different genders towards selfservice show different levels of avoidance under different indicators. Among them, the difference is significant under the D-score index, while the average reaction time under this index is not significantly different, and the difference is not significant under the explicit attitude difference index. In addition, we learned about the familiarity of these interviewed people with financial self-service transaction equipment, and the data are recorded as shown in Figure 2.

The 40 interviewed people all have a certain understanding of financial self-service transaction equipment. According to the data, we can understand that ATM machines and bank ticket machines have been widely popularized in our current daily lives. The usage rate is high.

According to the interviewed financial self-service transaction service experiencers (Figure 3), the financial selfservice machine must complete a series of complex actions such as card reading, uploading, verification, testing, query, money suction, money dispensing, transfer, and printing. However, the fly in the ointment is that many self-service kiosks do not give full play to their advanced functions (Table 3). Some self-service kiosks often fail and fail to provide services and often make mistakes or swallow cards, and even some personal kiosks cannot be repaired after they fail due to aging. They have become simple decorations that no one cares about. Therefore, in this questionnaire survey, the 40 interviewed people have a further understanding of the experience of self-service transaction terminal service equipment. The data are recorded as shown in Figure 4.

According to the user's proficiency in the interactive design operation of the financial transaction self-service terminal service equipment interface and the frequency of use, users are roughly divided into four categories: novice users, mainstream users, expert users, and casual users. Every user will transform from a novice user to a mainstream user. Through in-depth research on novice users and casual users, the research and analysis are conducive to the solution of usability of nonfunctional problems in interactive design. Each user will have higher new requirements for the interactive design of the man-machine interface such as aesthetic requirements and functional requirements, so listening to the user's requirements for the functionality of the device will help to improve the design of the man-machine interface interaction. Details are redesigned The wireless communication network is combined with the financial self-service transaction service terminal to transform the experimental test results, and the data are recorded as listed in Table 4.

The application of wireless communication network in financial self-service transaction services greatly reduces the time for business processing, simplifies the steps required for transaction business, provides great convenience, and has the characteristics of easy-to-understand wireless operation, so there is a wide range of audience. 


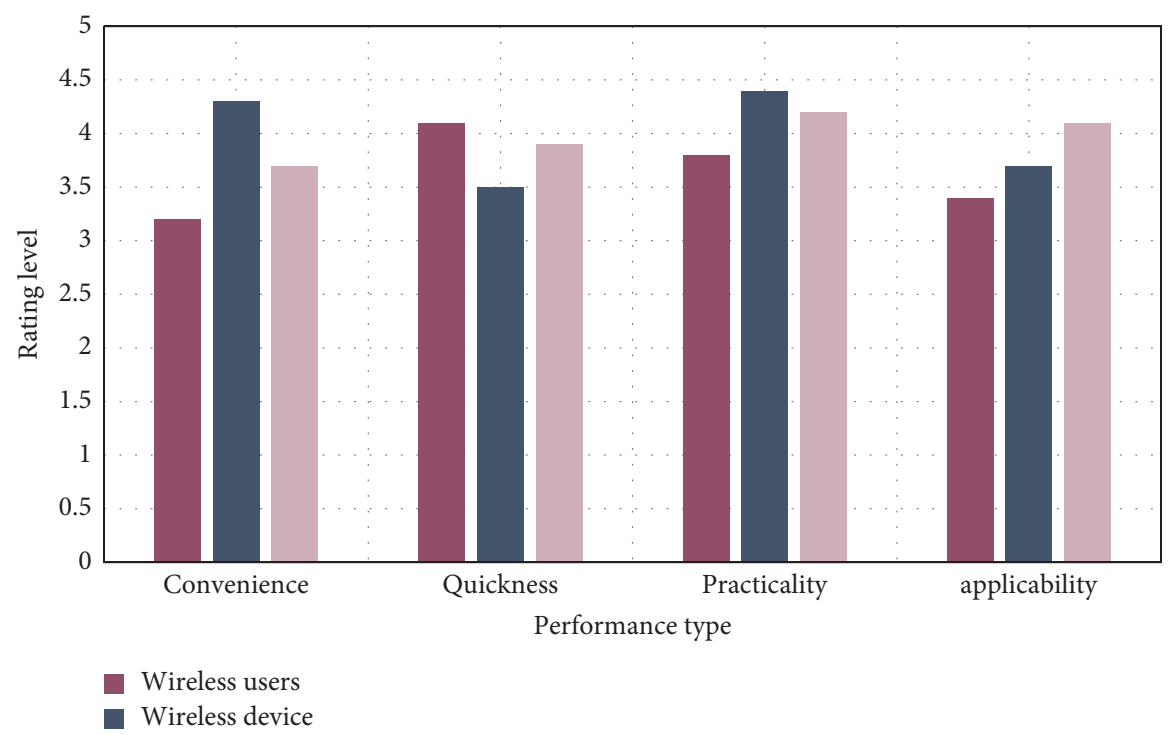

Figure 1: Performance analysis of wireless communication network applications.

TABLE 1: Basic information of the interviewed people.

\begin{tabular}{lccc}
\hline Education level & First use & Used a few times & Frequently used \\
\hline Primary school & 3 & 3 & 4 \\
Junior high school & 2 & 5 & 3 \\
High school or technical secondary school & 4 & 4 & 2 \\
College degree or above & 5 & 1 & 4 \\
\hline
\end{tabular}

TABle 2: Differences in preferences of different genders for financial self-service transactions.

\begin{tabular}{lccc}
\hline Statistical indicators & Group & Mean & Standard deviation \\
\hline \multirow{2}{*}{ D score } & Female & 0.43 & 0.32 \\
& Male & 0,32 & 0.34 \\
\multirow{2}{*}{ Response time difference } & Female & 342.9 & 284.5 \\
& Male & 298.5 & 358.1 \\
\multirow{2}{*}{ Poor explicit attitude score } & Female & 2.38 & 1.28 \\
& Male & 2.27 & 0.98 \\
\hline
\end{tabular}

Since the after-sales service problems of self-service transaction service equipment belong to the management of the manufacturer, this makes the management of financial self-service transaction service terminals more difficult. In this regard, some interviewees expressed that there are problems in the combination of wireless communication network and financial self-service transaction services, which are reflected in Figure 5.

Due to the use of information and source division models based on network technology, Internet finance on the one hand reduces the average transaction cost of traditional products and services, and on the other hand, it increases the degree of information asymmetry in our lending process. SME loans combine high efficiency, low cost, and cost-effective management with distributed funds and low default rates. The benefits of this new Internet consumption model are often in line with the concept of business integration. It incorporates disadvantaged groups and remote communities that are mainly involved in eliminating money into the traditional financial service system and uses efficient mobile payment methods and big data processing to give them flexibility and speed in financial services and products, while increasing the size and depth of tolerance.

Financial consumers are also paying more and more attention to user experience, are no longer satisfied with the services provided by traditional financial institutions, and are increasingly pursuing personalized and customized financial services. This demand will become stronger today with the improvement of information technology. We can develop integrated software management functions and distribution and automated upgrades for ATMs of different developers. In order to solve the problems of cross-bank business handling, the four interviewed people adopted the financial self-service transaction dimension summary (Table 5).

According to the data provided in Table 5, the two dimensions of usefulness and ease of use, as well as the social environment that has attracted the attention of the interviewed people, also illustrate the advantages of financial self-service 


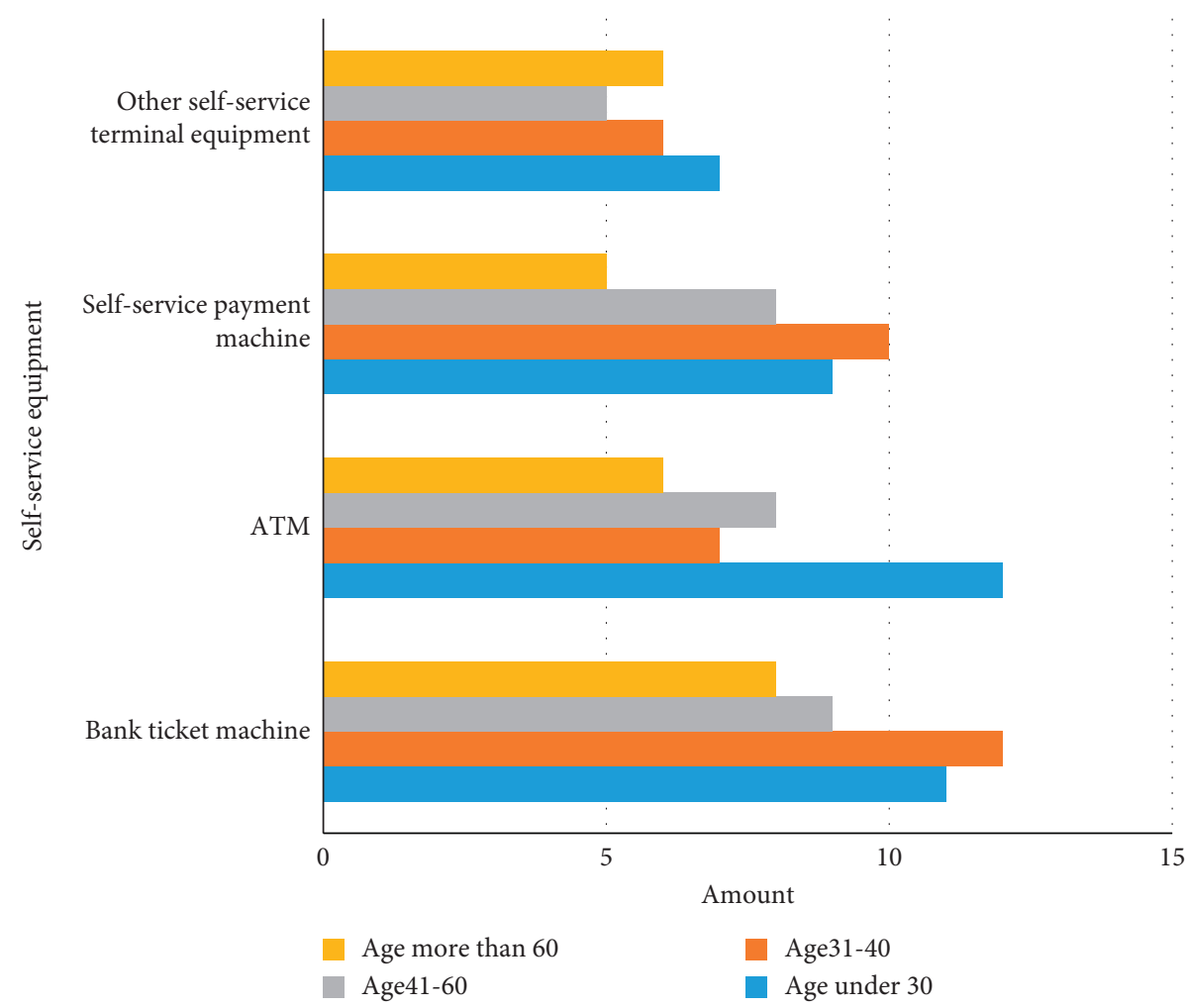

Figure 2: The survey respondents' usage statistics of self-service terminal equipment.

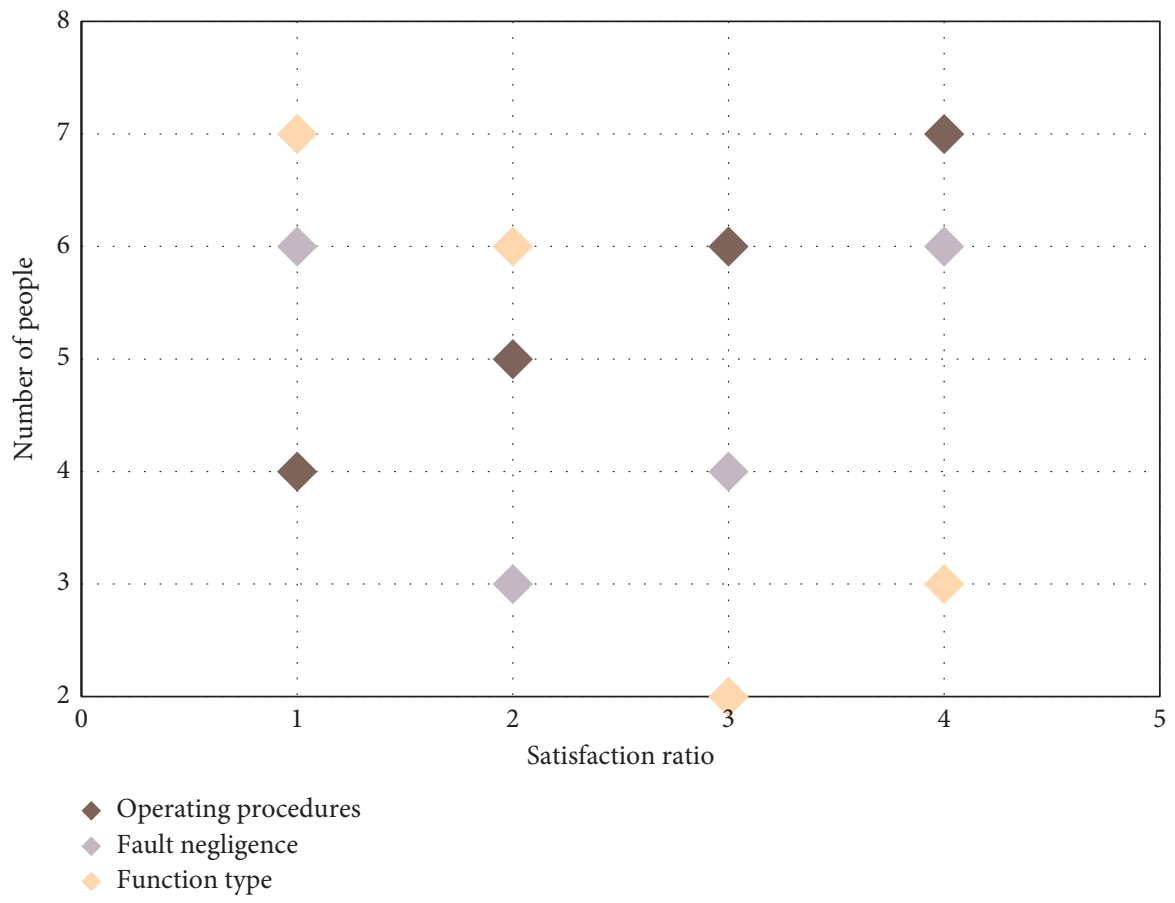

Figure 3: Problems in the current self-service machine business processing process.

transaction services. In the previous article, we mentioned the current problems of information asymmetry, incomplete information, and reputation risks in financial autonomous transaction services. In the face of these problems, wireless communication networks need to be updated and data monitored to enhance system security (Figure 6). With the help of Internet technology, it breaks the limitations of the working time and space of the bank in the past, uses the business data analysis system for risk management, comprehensively enhances the bank's capabilities, simplifies operations, and reduces costs. 
TABLE 3: Self-service transaction server failure statistics table.

\begin{tabular}{lcccc}
\hline$<!-$ Col Count:5 F0E0 Frequency of failure & Machine malfunction & Wrong account & Bank card is stuck & Slow response \\
\hline Almost none & 2 & 1 & 2 & 2 \\
Occasionally & 5 & 4 & 4 & 1 \\
Frequently & 3 & 5 & 4 & 7 \\
\hline
\end{tabular}

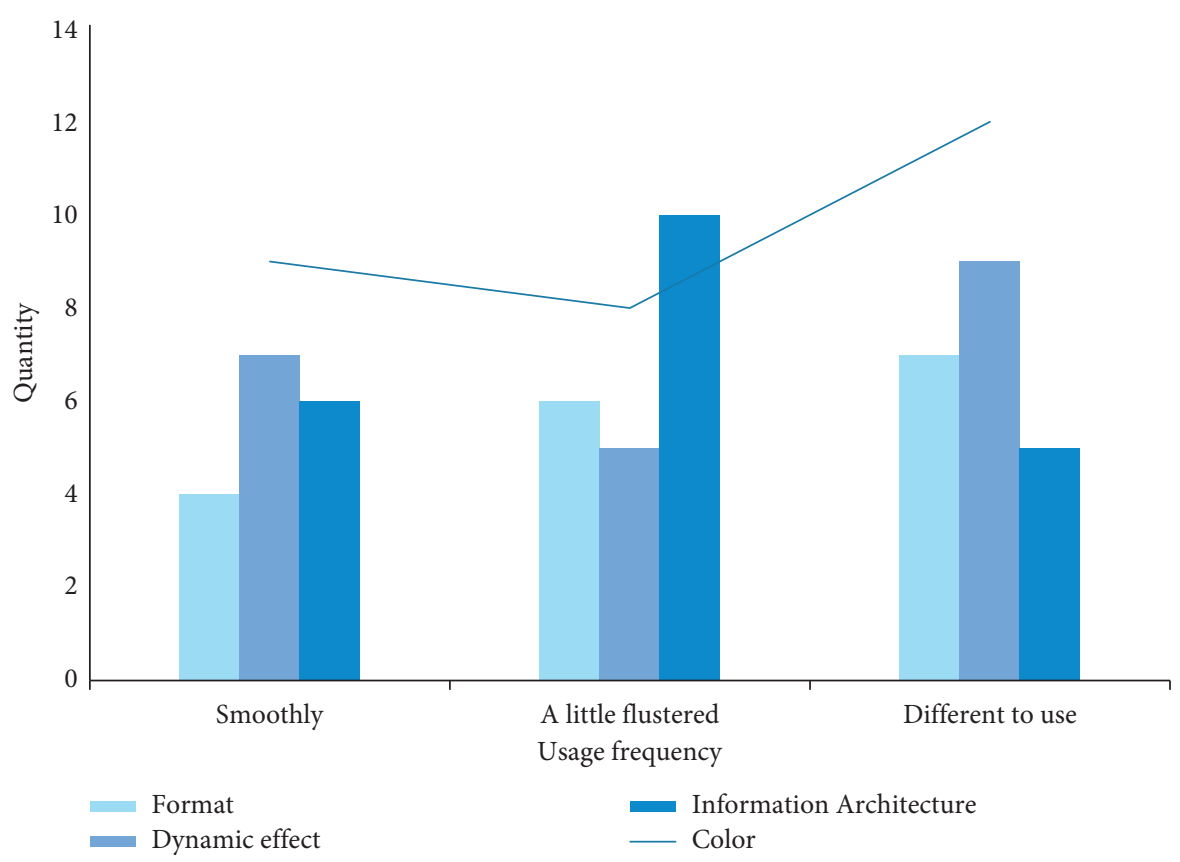

FIgURE 4: Service evaluation of financial self-service transaction equipment by interviewed mass users.

TABLE 4: Combination of wireless communication network and financial transaction self-service terminal.

\begin{tabular}{|c|c|c|c|c|}
\hline Project type & Withdrawal & Transfer & Pay & Inquire \\
\hline Wireless communication network interface control (1-10) & 8 & 9 & 8 & 9 \\
\hline Total time spent on a task (minutes) & 2.5 & 2.1 & 2.6 & 2.4 \\
\hline Success rate & $100 \%$ & $100 \%$ & $100 \%$ & $100 \%$ \\
\hline Number of operation steps & 4 & 5 & 4 & 3 \\
\hline Comprehension of wireless communication network interface (1-5) & 4 & 5 & 3 & 5 \\
\hline
\end{tabular}

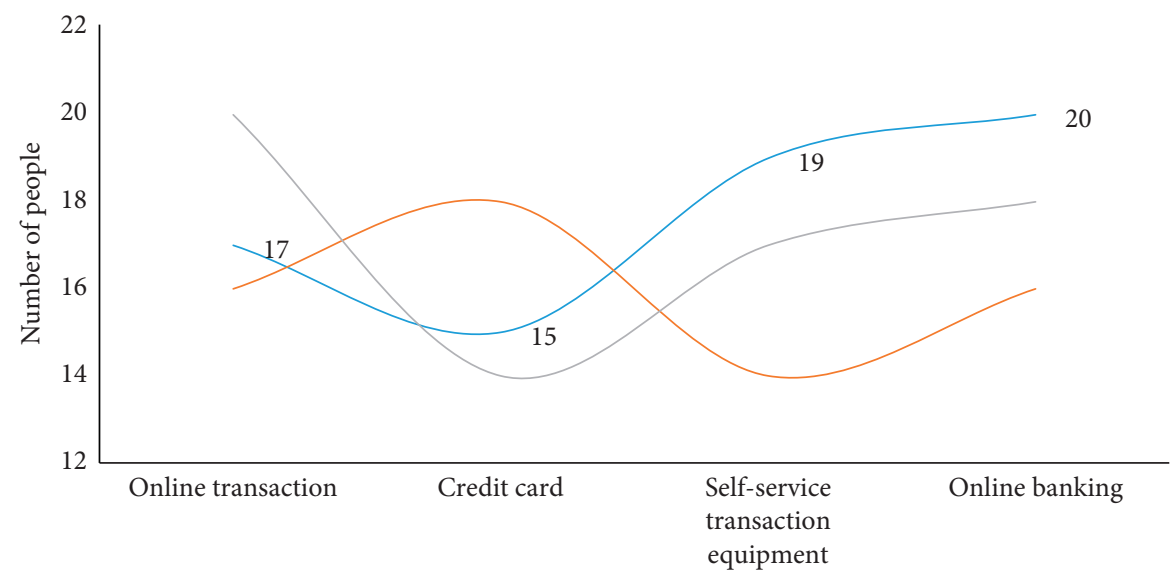

Different self-service transaction methods

- Incomplete information

- Information asymmetry

_ Prone to credit risk

FIgURE 5: Problem statistics of different self-service transaction devices. 
TABLE 5: Dimensions of adopting financial self-service transaction services.

\begin{tabular}{lllll}
\hline Classification dimension & 1 & 2 & 3 & 4 \\
\hline Usefulness and ease of use & $\sqrt{ }$ & $\sqrt{ }$ & $\sqrt{ }$ & $\sqrt{ }$ \\
Cost perception & $\sqrt{ }$ & & $\sqrt{ }$ \\
Self-efficacy & $\sqrt{ }$ & $\sqrt{ }$ & $\sqrt{ }$ \\
Interpersonal environment & $\sqrt{ }$ & $\sqrt{ }$ \\
Social environment & & $\sqrt{ }$ \\
\hline
\end{tabular}

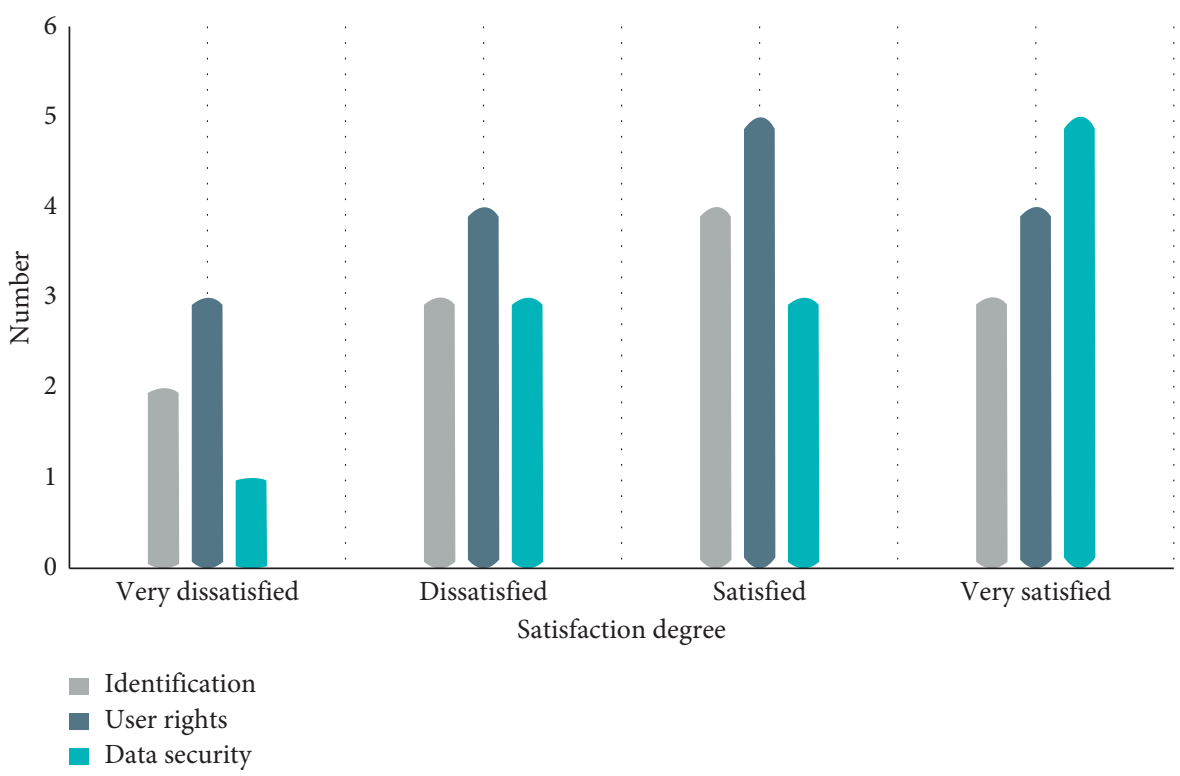

FIGURE 6: Statistics of people's satisfaction with different factors of system security.

To sum up, financial self-service terminals have been qualitatively improved in terms of technology, facilities, and channels. These changes provide end users with a new work experience, improve work efficiency, and reduce labor costs.

\section{Conclusion}

The financial self-service transaction service terminal system better realizes the related functions of deposit, withdrawal, transfer, and other requirements, with faster running speed and stable performance. When a user starts a transaction at the personal service terminal, the individual commercial terminal adopts the user's original structure, makes a simple entry decision, and then aggregates the data to the intermediate trading platform. The intermediate trading platform performs more complex authentication and will meet the requirements after the data are compiled again to the back-end error correction system and the back-end core processing system for transaction processing, it is gradually transferred to the selfservice terminal of self-service farmer finance in the opposite direction, and finally, a complete transaction is completed. The intermediate business data processing platform processes nonaccounting data, which reduces the burden of the bank's back-end core host, makes the back-end core host mainly process accounting data, reduces the probability of database lock tables, improves host efficiency, and makes the back-end core host version uniform. The transaction is processed through the intermediate business platform and is decomposed into multiple transaction steps, which increases the flexibility of transaction definition and adapts to the changing needs of intermediate business. Self-service terminals can provide people with transaction or inquiry services at anytime and in anyplace. With the continuous improvement of urbanization and informatization, self-service machines will be full of streets and alleys. The research on wireless communication network and financial self-service transaction service market conducted in this study has a certain significance. Through these studies, it is helpful to predict the development trend and prospects of financial transaction self-service terminals and at the same time can summarize the actual implementation steps to guide the construction of financial transaction self-service terminal project. The self-service access service system mainly deals with structured data, but in the information age, there are more and more unstructured data, and the processing of unstructured data can be considered in the later period.

\section{Data Availability}

Data sharing is not applicable to this article as no datasets were generated or analyzed during the current study.

\section{Conflicts of Interest}

The author declares that there are no conflicts of interest with any financial organizations regarding the material reported in this manuscript. 


\section{References}

[1] B. Mei, H. Hu, and N. Rouphail, "Simulation model for studying impact of vehicle-to-vehicle wireless communications on traffic network operations," Transportation Research Record, vol. 2189, no. 1, pp. 107-115, 2018.

[2] N. Economides and P. Jeziorski, "Mobile money in Tanzania," Marketing Science, vol. 36, no. 6, pp. 815-837, 2017.

[3] G. Zanarone, D. H.-F. Lo, and T. L. Madsen, "The doubleedged effect of knowledge acquisition: how contracts safeguard pre-existing resources," Strategic Management Journal, vol. 37, no. 10, pp. 2104-2120, 2016.

[4] B. Grdoi, E. Skreli, and D. Imami, "Determinants of sustainable relationships in the Albanian apple production sector," International Journal on Food System Dynamics, vol. 7, no. 1, pp. 50-65, 2016.

[5] J. Y. Yeh and C. H. Chen, "A machine learning approach to predict the success of crowdfunding fintech project," Journal of Enterprise Information Management, 2020.

[6] H. Geun, H.-Y. Kim, and Suh, "A study on the VAT taxation for the financial service and education service - in an aspect of revised tax law practices and education law," Journal of Tax Studies, vol. 16, no. 4, pp. 83-116, 2016.

[7] L. Li and H. Li, "Analysis of financing risk and innovation motivation mechanism of financial service industry based on internet of things," Complexity, vol. 2021, no. 3, 9 pages, Article ID 5523290, 2021.

[8] A. Estrella-Ramon, M. Sánchez-Pérez, and G. Swinnen, "How customers' offline experience affects the adoption of online banking," Internet Research, vol. 26, no. 5, pp. 1072-1092, 2016.

[9] M. Barkhordari, Z. Nourollah, H. Mashayekhi, Y. Mashayekhi, and M. S. Ahangar, "Factors influencing adoption of e-payment systems: an empirical study on Iranian customers," Information Systems and E-Business Management, vol. 15, no. 1, pp. 89-116, 2017.

[10] L.-M. Rehnen, S. Bartsch, M. Kull, and A. Meyer, "Exploring the impact of rewarded social media engagement in loyalty programs," Journal of Service Management, vol. 28, no. 2, pp. 305-328, 2017.

[11] S. Alaei, F. Alhani, and H. Navipour, "The financial transaction between counseling and nursing care service centers (CNCSCs) and their clients: a qualitative study," BMC Health Services Research, vol. 18, no. 1, pp. 282-289, 2018.

[12] E. E. Izogo, "Should relationship quality be measured as a disaggregated or a composite construct?" Management Research Review, vol. 39, no. 1, pp. 115-131, 2016.

[13] F. Cuandra, "Pandangan pengguna internet terhadap minat dalam adopsi internet banking pada masyarakat kota batam, provinsi kepulauan riau, Indonesia," SKETSA BISNIS, vol. 7, no. 1, pp. 27-36, 2020.

[14] F. Zhu, C. Zhang, Z. Zheng, and A. Farouk, "Practical network coding technologies and softwarization in wireless networks," IEEE Internet of Things Journal, vol. 8, no. 7, pp. 5211-5218, 2021.

[15] S. Thangalakshmi and A. M. Ezas, "Congestion management in deregulated power systems using generator rescheduling with particle swarm optimization," Journal of Computational and Theoretical Nanoscience, vol. 14, no. 9, pp. 4416-4423, 2017.

[16] M. Adil, M. K. Khan, M. Jamjoom, and A. Farouk, "MHADBOR: ai-enabled administrative distance based opportunistic load balancing scheme for an agriculture internet of things network," IEEE Micro, vol. 42, 2021.
[17] L. E. Burman, W. G. Gale, S. Gault, B. Kim, J. Nunns, and S. Rosenthal, "Financial transaction taxes in theory and practice," National Tax Journal, vol. 69, no. 1, pp. 171-216, 2016.

[18] Z. Ismail and P. Khembo, "Determinants of energy poverty in South Africa," Journal of Energy in Southern Africa, vol. 26, no. 3, pp. 66-78, 2017.

[19] R. Šperka and I. Szarowská, "Financial transaction taxation in agent-based simulation,” M: Ekonomie a Management, vol. 19, no. 2, pp. 176-187, 2016.

[20] C. k. Ayo, A. A. Oni, O. J. Adewoye, and I. O. Eweoya, "Ebanking users' behaviour: e-service quality, attitude, and customer satisfaction," International Journal of Bank Marketing, vol. 34, no. 3, pp. 347-367, 2016.

[21] T. Nguyen and S. Pergamenchtchikov, "Approximate hedging with constant proportional transaction costs in financial markets with jumps," Theory of Probability and Its Applications, vol. 65, no. 2, pp. 224-248, 2019.

[22] M. Naseri, M. A. Raji, M. R. Hantehzadeh, A. Farouk, A. Boochani, and S. Solaymani, "A scheme for secure quantum communication network with authentication using GHZ-like states and cluster states controlled teleportation," Quantum Information Processing, vol. 14, no. 11, pp. 42794295, 2015.

[23] E. Lepinette and T. Q. Tran, "Consumption-investment optimization problem in a Lévy financial model with transaction costs and làdlàg strategies," Mathematics and Financial Economics, vol. 14, no. 3, pp. 399-431, 2020.

[24] X. Xu, J. Ma, and X. Xie, "Convergence of Markovian price processes in a financial market transaction model," Operational Research, vol. 17, no. 1, pp. 239-273, 2017.

[25] A. Amri, H. Zainal, M. Ramadhini, F. Maulana, and M. Firdaus, "Financial transactions flow chart of fish marketing at fish landing center (PPI) lhok pawoh," Jurnal Inotera, vol. 5, no. 1, pp. 56-62, 2020.

[26] K. J. Laverierre and M. H. Behrens, "')"The US department of labor"'c心“"," The Journal of Investment Compliance, vol. 17, no. 4, pp. 1-22, 2016.

[27] P. Shome and J. G. Stotsky, "Financial transactions taxes," Social Science Electronic Publishing, vol. 95, no. 77, pp. 2-3, 2016.

[28] C. Li, P. Liu, C. Zou, F. Sun, J. M. Cioffi, and L. Yang, "Spectral-efficient cellular communications with coexistent one-and two-hop transmissions," IEEE Transactions on Vehicular Technology, vol. 65, no. 8, pp. 6765-6772, 2015.

[29] C. Wang, "Analyzing the effects of cross-border e-commerce industry transfer using big data," Mobile Information Systems, vol. 2021, no. 8, 12 pages, Article ID 9916304, 2021.

[30] M. Laila, M. Muis, and D. A. S. Parawansa, "The impact of consumer interests, security risks, and financial behavior on new transaction tool (e-money)," Hasanuddin Journal of Business Strategy, vol. 2, no. 3, pp. 83-91, 2020. 